DOI: $10.14451 / 2.122 .90$

\title{
ПРОЦЕССНЫЙ ПОДХОД К АНАЛИЗУ ВНУТРИФИРМЕННОГО РЫНКА ТРУДА
}

\author{
(C) 2018 Горбанев Сергей Викторович \\ кандидат экономических наук, доцент кафедры менеджмента и региональной экономики \\ Майкопский государственный технологический университет \\ 385000, г. Майкоп, ул. Первомайская, 191 \\ (c) 2018 Зарубин Владимир Иванович \\ доктор экономических наук, профессор \\ Майкопский государственный технологический университет \\ 385000, г. Майкоп, ул. Первомайская, 191 \\ E-mail: zarubin.vi18@yandex.ru
}

Цель публикации настоящего материала состоит в раскрытии особенностей процессного подхода к анализу внутрифирменного рынка труда. На основе проведенного исследования обосновано, что использование процессного подхода при формировании и регулировании внутрифирменного рынка труда предусматривает его представление в виде взаимосвязанных процессов. Применение процессного подхода к анализу предоставляет возможность повысить организационную гибкость и оперативность в процессах управления внутрифирменным рынком труда.

Ключевые слова: Внутрифирменный рынок труда, процессный подход, человеческий капитал, трудовые ресурсы.

Разнообразие рынков труда (многообразие видов занятости, различная степень локализации) определяет необходимость их объективной классификации, обусловливающей их характер и специфику функционирования. Например, Пайор М. и Доринджер П. исследовали так называемую модель «дуального рынка труда», которая представлена первичным и вторичным секторами [1]. Рынки первичного сектора отличаются высокой заработной платой, стабильной занятостью, достойными условиями труда, стандартной совокупностью положенных социальных гарантий, возможностью профессионального роста [2]. Для рынков вторичного сектора данные показатели не характерны.

В свою очередь, Г. Стендинг дополнил концепцию дуального рынка и предложил модель сегментированного рынка труда с выделенными сегментами:

- рынок специалистов высшей квалификации;

- рынок квалифицированных кадров;

- рынок труда рабочих профессий;

- рынок труда малоквалифицированных работников;

- остаточный рынок труда [3].

В соответствии с классификацией К. Керра рынка труда разделяются в зависимости от механизмов регулирования занятости: рынки ре- месленных занятий и рынки индустриальные. Границы индустриального рынка определяются пределами предприятия. В свою очередь, границы ремесленного рынка определяются географическими и профессиональными факторами. В данном контексте индустриальный рынок по существу является и описывается моделью внутреннего рынка труда. Регулирующий механизм, в этом случае, представляет собой «лестницу рабочих мест», определяется правилами вхождения на рынок, правилами организации использования и перемещения рабочей силы. Механизм регулирования ремесленных рынков представляется реализацией договорных отношений между работодателем и профсоюзом в процессах найма, использования и увольнения.

Специфика внутреннего рынка труда состоит в необходимости привлечения к свободным рабочим местам уже нанятых на предприятие работников, а также в привязке размеров оплаты труда к конкретным рабочим местам. Регулирование внутрифирменных потоков трудовых ресурсов производится в процессе управления предприятием с учетом внутриорганизационных институтов. Важнейшим достижением Керра считается обоснование им взаимосвязи индустриальных рынков и общенациональных рынков труда. Таким образом, именно параметры и развитие индустриальных рынков во мно- 
гом определяет характеристики мобильности рабочей силы, спрос, предложение и цену труда на внешнем рынке.

Понятие внутреннего рынка труда (Internal Labor Market) ввел Дж. Данлоп, основываясь, по существу, на процессном подходе [4]. В работах этого ученого показано, что различие в цене труда свойственны не только внешнему рынку, но и для предприятия или его подразделения. В свою очередь множество видов деятельности, представленных на общем рынке труда, рассматривается как совокупность разнообразных кластеров, включающих работы, группируемые по технологиям, организационные модели и социальным традициям.

Внешний рынок труда воспроизводит потоки рабочей силы из внешней среды на предприятие и от предприятия во внешнюю среду. В данном случае именно во внешней среде осуществляется профессиональная и квалификационная подготовка [5]. Внутренний рынок труда составляют процессы подготовки и движение рабочей силы в пределах предприятия.

Внешний рынок труда (национальный, территориальный, региональный) интегрирует множество внутренних (организационных) рынков. Очевидно, что от функционирования внутренних рынков зависят параметры потоков рабочей силы из внешней среды на предприятие и от предприятия на внешнюю среду. Чем больше предприятие высвобождает работающих, тем становится более перегруженным внешний рынок. Численность занятых на внешнем рынке в значительной степени определяется не только действиями по высвобождению рабочей силы, но и активностью работодателей в сфере расширения своего бизнеса. Вместе с тем, технологический фактор также оказывает существенное влияние не только на характеристики внутреннего рынка труда на предприятии, но и отражается на параметрах (спрос, предложение, цена) на внешнем рынке труда. Таким образом, возникает необходимость в актуализации научных исследований процессов функционирования внутренних рынков. Современное состояние рынка труда характеризуется перманентным расширением проблемного поля. Причины расширения множества проблем состоят не только в углублении и расширении научных теорий, описывающих экономику рынка труда, но и в увеличивающемся структурном рыночном дисбалансе, необходимости внедрения технических новшеств, повышении степени информатизации воспроизводственных систем и общества [6]. Необходимо отметить, что известные законы классической экономики труда не совсем точно описывают организационные и трудовые процессы, на основе конкурентной модели. Это положение обосновали Пайор М. и Доринджер П. [7] Они предложили к использованию концептуальную эталонную модель внутреннего рынка, предоставляющую возможность исследования факторов, определяющих характер социально-экономических отношений, имеющих место в процессах обмена рабочей силы во внутренней и внешней среде организации. Рынок труда эти исследователи рассматривали в виде двухсекторной модели. В данной модели внутренний рынок представлен внутрифирменным рынком труда и внутренним рынком. Данные рынки отличаются их ролью в общем процессе трудовой занятости. Внутрифирменный рынок представлен трудовыми ресурсами во внешней среде и работодателями конкретных организаций. Внутренний рынок описывают процессы между работниками, труд которых может применяться в разных процессах внутри организации и организационными управленцами, связанными с конкретными процессами.

Структура занятых в национальной экономике значительно отличается по приоритетности вида деятельности в воспроизводственной сфере различных стран. В значительной степени это отражается и на специфике внутренних рынков труда. Социально-трудовые отношения в организации, их характеристика и разнообразие в свою очередь зависят от внутриорганизационных факторов, обеспечивающих их регулирование в зависимости от особенностей групп работников и организационных процессов, в которых данные работники используются.

Широко известна классификация групп работников по признаку характера использования их в рамках организации, а именно индустриальная, ремесленная, вторичная и окладная группы. Так, индустриальная группа объединяет рабочих, занятых в основных воспроизводственных процессах. Ремесленная группа объединяет узких специалистов, инженеров, техников. Во вторичной группе сосредоточены работники, участвующие в процессах функционирования инфраструктуры. Окладная группа предусматривает описание трудовых ресурсов в процессах с повременной оплатой. Очевидно, что инструмен- 
тарий анализа социально-трудовых отношений, факторов и условий функционирования внутрифирменных рынков труда определяется, прежде всего, спецификой группы работников организации.

Если описанная выше модель внутрифирменного рынка труда ориентирована на социально-экономические отношения внутри отдельных групп работников, то модель Д. Биллса ориентирована на анализ и исследование основных структурных компонентов: рынки, иерархия, позиция руководства и структура внутрифирменного рынка труда [8]. В данном случае функционирование внутрифирменных рынков труда является специфической формой реагирования предприятия на внутренние возмущающие воздействия. Инструменты и методы управления, стратегия использования трудовых ресурсов являются по существу такими организационными реакциями. При этом процессы функционирования непосредственных субъектов труда (работников организации) в данной модели не исследуется. Вопросы, относящиеся к проблемам регулирования внутрифирменного рынка, решаются в зависимости от позиции менеджмента организации, характера его функций предпочтения и внутриорганизационных процессов.

Известно, что трудовые ресурсы относятся к нематериальной форме активов организации. В современных условиях развития экономики организаций эта форма активов не может не учитываться при анализе возможностей предприятия. Общепризнанным является факт, что экономическая эффективность организации в равной степени зависит как от материальных, так и от нематериальных ресурсов. Различные виды ресурсов тесно взаимосвязаны между собой. Организационно-финансовые ресурсы или капитал обусловливают возможность инвестиций в развитие интеллектуального капитала. Интеллектуальный капитал непосредственно влияет на процессы формирования и развития человеческого капитала и наоборот. Таким образом, стратегии развития человеческого капитала основываются на формировании организации и оптимизации использования интеллектуального капитала, являющимся ресурсным компонентом инновационного развития организации.

Анализ и исследование интеллектуального капитала методологически основывается на положениях теории управления ресурсами в орга- низации с учетом особенностей и специфики ее деятельности. Очевидно, что концептуальные и организационные модели интеллектуального капитала различных организаций являются уникальными, в силу специфики и особенностей не только организационных процессов, но и характеристик человеческого капитала. Тем не менее, в настоящее время наукой выработаны отдельные общие подходы к структуризации нематериальных, в том числе и интеллектуальных и трудовых активов.

Интеллектуальный капитал, ориентированный на характеристику субъектов организационных отношений может быть разделен на человеческий, организационный, клиентский, управленческий и т.д. Термины, характеризующие специфику и многообразие нематериальных активов, включают: бренд, интеллектуальная собственность, эффективность НИОКР и т.д. [9]

Интеллектуальный капитал в современной теории капитализации ресурсов представлен тремя составляющими: человеческий, организационный и клиентский капитал. [10] Представляется, что множество составляющих интеллектуального капитала необходимо расширить, исключив из них человеческий капитал. Это связано с тем, что организация, обладая значительным человеческим капиталом, может не обладать интеллектуальным капиталом вообще. Очевидно, что зависимости между структурными компонентами интеллектуального капитала могут быть организованы на основе различных модельных конструкций. Вместе с тем, при относительной независимости интеллектуальный и человеческий капитал состоят в тесной взаимосвязи. То есть, человеческий капитал, обладающий соответствующими свойствами или характеристиками, может воспроизводить интеллектуальный капитал, который, в свою очередь, также может активизировать развитие и воспроизводство человеческого капитала. Речь идет о модели замкнутого воспроизводственного цикла.

Таким образом, содержание человеческого капитала определяет характеристики и параметры всех других составляющих интеллектуального капитала. Именно человеческий капитал определяет качества и характеристики организационного, научного и других видов интеллектуального капитала. Например, образовательная структура персонала организации, уровень 
его компетентности влияет на формирование капитала инноваций (патенты, изобретения, проекты и т.д.), а также капитал процессов и структурный капитал.

Значимая роль в формировании интеллектуального капитала имеет этап проектирования процессной структуры организации. В данном случае функционально-процессное содержание организационной системы влияет на разнообразие и параметры интеллектуального капитала. В свою очередь, организационная система предваряет проектирование системы управления, представляющей собой совокупность функциональных воспроизводственных циклов. Процессы, реализуемые в границах организации, будут эффективны в зависимости от рациональности и качества сформированной системы управления организацией.

Процессно-структурная методология является одним из действенных подходов к проектированию системы управления организацией. В соответствии с ней проектирование процессов первично по отношению к проектированию структуры. То есть, разнообразие организационных процессов и их содержание будут определять и структурную специфику организации. Человеческий капитал, в данном случае, является важнейшим фактором, от которого зависит не только качество сформулированной стратегии и миссии (на начальном этапе формирования организации), но и другие структурные и процессные характеристики организации. Как правило, стратегические и тактические планы по формированию и развитию организации ориентированы прямо или опосредованно на развитие человеческого капитала. Все элементы алгоритмов проектирования организационных систем, процессов, и операций предусматривают учет человеческих ресурсов в виде действий по определению потребности в необходимых трудовых ресурсах по расчету затрат на заработную плату персонала, разработку организационных институтов и пр.

Важными параметрами человеческого капитала являются уровень образовательного потенциала, физические и умственные способности персонала. Все эти характеристики непосредственным образом отражаются на стоимостной оценке нематериальных активов организации. «В теории, эти внедренные знания независимы от людей, которые их развивают - и, следовательно, они относительно стабильны - отдель- ный специалист может исчезнуть, но это не уменьшит запаса знаний, внедренных в компании» [11].

Известны два основных подхода в теории управления к формированию и анализу функционирования организации: функциональный и процессный. Специфика функционального подхода отражается в следующих положениях:

- результативная ответственность распределяется между исполнителями;

- увеличивается вероятность конфликтов между подразделениями, реализующими разные функции. Это отражается на оперативности разработки и принятии решений, а также на процессах реализации изменений;

- снижается взаимосвязь между организационной эффективность. И эффективностью функциональных подразделений;

- увеличение функциональной эффективности происходит за счет снижения расходов ресурсов, задействованных в процессе реализации конкретной функции.

Организационные структуры и подразделения, сформированные по функциональному принципу ориентированы, как правило, на реализацию строго функциональных целей. Имеющая место межфункциональная конкуренция (конфликтность) ограничивает результативность процесса реализации стратегических целей организации. Кроме того, использование иерархического принципа в построении организационной структуры обеспечивает присутствие искажений и задержек в процессах принятия управленческих решений. Вместе с тем, в организации зачастую отсутствует общий технологический регламент, в котором в полной мере была представлена технология реализации соответствующей функции. При реализации процессного подхода действия по подготовке, использованию и перемещению рабочей силы представляются в виде взаимосвязанных элементарных систем, имеющих входы, выходы, потребляющих ресурсы и обладающих определенной эффективностью и ценностью для организации.

Преимущества процессного подхода к анализу внутрифирменного рынка труда выражаются в реализации программно-целевого подхода в управлении организацией и трудовыми процессами. В данном случае объектом управления являются индикаторы результативности процессов. Гибкость и оперативность в выработ- 
ке управляющих воздействий по регулированию внутреннего рынка труда повышается за счет превалирования горизонтальных и межфункциональных связей, что в свою очередь обеспечивает снижение уровня конфликтности в организации.

Разделение процесса функционирования организации на единичные ценностно-ориентированные процессы повышает мотивацию в достижении процессных результатов деятельно- сти персонала при увеличении степени согласования коллективных действий. В сложившихся экономических условиях невозможно обеспечить выживаемость предприятий без использования в управлении принципов процессного и системного подходов, сущность которых состоит в представлении организации, как системы взаимосвязанных динамичных интегрированных процессов, обеспечивающих достижение конкретных процессных и организационных целей.

\section{Библиографический список}

1. Мариинкевич В.И., Соболева И.В. Экономика человека: учебное пособие для высш. учеб. заведений. Москва. 1995.

2. Белокрылов А.А., Белокрылова О.С., Вольчик В.В., Кетова Н.П. Рынок труда региона и его институциональная организация. Ростов-на-Дону. 2003.

3. Экономическая школа. Санкт-Петербург. 1992. Выпуск 2.

4. Dunlop J.T. Job Vacancy Measures and Economics Anabasis. In NBER, The Measurement and Interpretation of Job Vacancies: A Conference Receipt. New York. Colombia University Press. 1966.

5. Зарубин В.И., Овсянникова Т.А. Управление устойчивостью воспроизводственного комплекса региона. Майкоп, 2011.

6. Экономика труда / Под ред. Н.А. Волгина, Ю.Г. Одегова. Москва. 2004.

7. Doringer P., Piore M. Internal labor markets and manpower analysis /Heath. Lexing-ton. 1971.

8. Bills D B. Costs, Commitment and Rewards: Factors Influencing the Design and Implemantation of Internal Labour Markets // Administrative Sciense Quarterly .1987 № 32

9. Просвирина И.И. Интеллектуальный капитал: новый взгляд на нематериальные активы // Финансовый менеджмент. 2004. № 4.

10. Духнич Ю. Интеллектуальный капитал: составляющие, управление, оценка // https://www.cfin.ru

11. Davenport T, Prusak L. Working Knowledge: How organizations manage what they know. Boston, Mass.: Harvard Business School Press. 